\title{
Global governance for health
}

Experts in global health and health diplomacy have focused increasing attention on the impacts - on populations' health and health systems - resulting from non-health sector policies defined and implemented at the global level.

This trend explains the interest in the report by The Lancet-University of Oslo Commission on Global Governance for Health, published by the renowned British journal (Lancet 2014; 383:630-67). The report analyzes how the distribution of health risks is still extremely and unacceptably unequal, and that contrary to expectations, the current global governance system fails to protect the population's health, with disastrous effects on the poor, vulnerable, and marginalized.

Through their policies and actions, powerful global actors are responsible for many of these inequities. Such actors include transnational corporations, governments of powerful countries, and even UN agencies, which frequently ignore the negative effects of their initiatives on the populations' health and health systems. The Commission attributes such "political" determinants of health to a profound power asymmetry, most often determined by exclusive market interests.

The Report cites several examples, including the neoliberal fiscal austerity policies imposed by the "troika" (IMF, European Central Bank, and European Commission) on peripheral countries (vis-à-vis the central circuit of the capitalist economy), such as Greece, Portugal, Spain, and Ireland. These countries have suffered the resurgence of previously controlled diseases and the dismantling of public social and health institutions built over the course of the 20th century.

The Commission attributes the adverse effects of global political determinants of health to five dysfunctions in the global governance system (democratic deficit, weak accountability mechanisms, institutional "stickiness", inadequate policy space, and missing or nascent institutions), and proposes three principal initiatives: (1) Creation of a multi-stakeholder platform on global governance for health, including global civil society, the UN, the business community, and NGOs, to function as a discussion forum for policies and agenda-building and the evaluation of their impact on health and health equity, in addition to proposing adequate solutions and overcoming barriers to their implementation; (2) An independent scientific monitoring panel on the influence of global governance processes on health equity through mandatory impact analyses on levels of health equity in international organizations; (3) Utilization of human rights instruments in health such as the Special Rapporteurs and stricter sanctions against a broad range of violations committed by non-state agents, through the international legal system.

The task at hand is to publicize the Commission's proposals (as CSP is now doing with this Editorial, in solidarity) and to mobilize the various stakeholders in promoting health equity and in correcting policies to make them more effective. An excellent opportunity is the current negotiation of the Global Development Agenda Beyond 2015, of the UN and its member states, guaranteeing that global policy and the governance mechanisms resulting from it definitively address the negative impacts of non-health sector policies on health.

The issue also includes drawing on countries like Brazil with equivalent proposals for joint action by government and civil society to block external forces identified as producing inequities or inducing poor health conditions, as with the tobacco and pesticide industries. The challenge also involves including health equity on the national agenda, which means fully and speedily achieving the principles set out in Art. 196 of the 1988 Federal Constitution and the comprehensive implementation of the Unified National Health System.

Paulo M. Buss

Escola Nacional de Saúde Pública Sergio Arouca, Fundação Oswaldo Cruz, Rio de Janeiro, Brasil.

Member of The Lancet-University of Oslo Commission. 